\title{
Experimental Analysis of Performance Improvement of a Modified Vapour Absorption System (VAS-GAX) for Cooling Applications
}

\author{
Suyambazhahan Sivalingam ${ }^{1 *}$, Sakthivel Thirumalai Gopal ${ }^{2}$, Vivek Pandey ${ }^{1}$, Mohanram Parthiban ${ }^{1}$ \\ ${ }^{1}$ Department of Mechanical Engineering, School of Mechanical, Chemical and Materials Engineering, Adama Science and \\ Technology University, Adama 1888, Ethiopia \\ ${ }^{2}$ Saveetha School of Engineering, SIMATS Deemed University, Chennai, Tamil Nadu 600077, India
}

Corresponding Author Email: suyamiitm@gmail.com

https://doi.org/10.18280/ijht.390623

Received: 3 November 2021

Accepted: 27 December 2021

\section{Keywords:}

VAS-GAX system, cooling applications, COP improvement, saving electrical energy, less environmental harm and lower losses

\begin{abstract}
Experiments on an enhanced "Generator-Absorber-Heat Exchanger" (GAX) Vapour Absorption System (VAS) for cooling purposes were carried out using water-ammonia in present study. The new experimental setup was fabricated using modern and complex technologies for the GAX absorption system which includes tiny heat exchangers, allowing the system to be both compact and efficient. The coefficient of performance (COP) of a system was analyzed for different temperatures of Generator, Condenser, Evaporator and Absorber. The results show that the maximum performance $(\mathrm{COP}=0.63)$ is achieved at $25^{\circ} \mathrm{C}$ Generator temperature. The system has a low carbon footprint because it does not use effluent water or tower electricity and invention enables the recovery of hot air, which may then be used for several drying applications, including agricultural drying, resulting in a fully cascaded system with a three-fold increase in Coefficient of Performance (COP). A modified VAS-GAX absorption system in present analysis be a good fit for highperformance modern cooling applications.
\end{abstract}

\section{INTRODUCTION}

The routinely used refrigerants in commercial refrigeration systems are causing several environmental issues. Various refrigerants are frequently used in vapour absorption refrigeration (VAR) and may give an improved option to lessen the environmental impact [1] of hydro chloro fluoro carbons (HCFC), chloro fluoro carbons (CFC) and hydr fluoro carbons (HFC) and maybe replace the vapour compression system (VCR) system. VAR provides several advantages, including lower losses, improved co-efficient of performance (COP), lower power consumption, and reduced environmental impact [2]. The absorption refrigeration system is not employed for commercial applications due to its low performance and thus requires development. Renewable energy is also the only solution for rural areas in distant areas where meeting electricity demand is difficult. VAR is capable of quickly adapting to renewable technologies such as solar photovoltaics and solar thermal systems. It enables rural cold storage even in the most remote areas. The temper Green technology is perfect for preserving tropical agricultural produce at temperatures ranging from 10 to $15^{\circ} \mathrm{C}$. The refrigeration process has seen significant technological advancements, but the basics of the process remain same. As a part of the ongoing search for newer technologies in research, valuable alternatives to the standard vapour-compression mechanism identified as typical vapour-compression system. In this work, a novel operating model of an alternate refrigeration system is built in a simple VCR system utilizing modern and complex technologies to improve system efficiency, minimize electrical energy consumption, and lessen environmental harm.
Srivastava et al. [3] performed a study on uses of renewable energy sources such as sun, wind, and geothermal, the $\mathrm{NH}_{3}$ $\mathrm{H}_{2} \mathrm{O}$ Absorption Refrigeration System offers a low-cost alternative to existing systems. The use of solar energy to create refrigeration systems has the most negligible impact on the environment and humans.

Boudéhenn et al. [4] developed and compared the performances of ammonia-water absorption chillers with cooling capacities of $5 \mathrm{~kW}$ and $100 \mathrm{~kW}$. The chillers were powered by solar energy or waste heat. In addition, a chilled cooling capacity of $100 \mathrm{~kW}$ was developed to produce ice by delivering a cooling effect at temperatures suitable for air conditioning. They showed that their design enabled quick start-up operation and adapted quickly to low/partial loads. Osta-Omar and Micallef [5] examined and optimized the vapour solution interface area on a miniature lithium bromide VARS, for various absorption rates. The miniature device could have applications for electronics cooling devices at miniature level. The system was equipped with an adiabatic absorber. The solution thickness was found to have the least effect on the absorption rate, with an optimum vapour solution interface area of $140 \mathrm{~cm}^{2}$.

Ramesh et al. [6] experimentally evaluated the performance of a shell and coil heat exchanger (SHX), which was a component of an $\mathrm{NH}_{3}-\mathrm{H}_{2} \mathrm{O}$ based VAR system. The $\mathrm{SHX}$ was explored for the heat transfer co-efficient (HTC) on the coil, which would significantly influence the total HTC and shape of the SHX. They found a shell side heat transfer coefficient of 510 to $650 \mathrm{~W} / \mathrm{m}^{2} \mathrm{~K}$ and a heat exchanger efficacy of 0.84 to 0.9 for the studied conditions. Jain et al. [7] investigated a100 $\mathrm{kW}$, combined vapour compression absorption integrated refrigeration system (VCAIRS) using low-grade, waste heat. 
The system was compared to a vapor compression-absorption cascaded refrigeration system (VCACRS), of same capacity. Electricity consumption for VCAIRS was 21.4 percent more than VCACRS. However, electricity consumed was $63 \%$ less compared to VCRS. Moreover, the second law effectiveness of VCAIRS, VCACRS, and VCRS were established at $27.9 \%$, $32.73 \%$, and $18.83 \%$, respectively. The VCACRS was found to be comparatively more energy-efficient cooling technology.

Al-Amir and Khudair [8] investigated a branched GAX absorption cycle operating with $\mathrm{NH}_{3}-\mathrm{H}_{2} \mathrm{O}$ pair. Under static conditions, the Engineering Equation Solver (EES) software was used for performance analysis. The results showed that when the temperature in the generator and evaporator rises, the mean COP and cooling capacity of the device rose, but as the temperature in the condenser rises, the mean COP and cooling capacity falls. In addition, the split ratio and ammonia content difference significantly impacted chiller absorption. Ponshanmugakumar and Rajavel [9] did experiments on vapour absorption generator. The phase change material (PCM) was used for thermal energy storage system in generator. The generator design was altered to accommodate PCM confinement and an average temperature of $60^{\circ} \mathrm{C}$ to $80^{\circ} \mathrm{C}$ for the heat energy available. PCM were made of combinations of paraffin wax, and graphite powder. Furthermore, the storage tank was assessed for thermal energy charging and discharging by changing the material composition.

Talpada and Ramana [10] reviewed the performance improvement of basic VAS with cycle modifications. An absorption refrigeration system must perform well in order to be a viable alternative to vapour compression refrigeration systems. Also, switching to absorption systems improves the efficiency of absorption cooling systems. The employment of a double- and semi-generator heat exchanger solution system improves cooling absorption effectiveness. The combination of compression-absorption and expulsive-absorption cycles improves the cooling performance of the absorption coefficient. Praveen et al. [11] analyzed a Vapor Absorption Refrigeration (VAR) system run with waste heat from an internal combustion (IC) engine's exhaust gas. The exhaust from a $1.5 \mathrm{~L}$ diesel engine was used. Sage Math 9.0 was used to analyse the VAR system. The heat transmission across various system components was compared with different VAR system temperatures, and the COP examined with varied generator temperatures. The results revealed that as the input temperature rises, the system's performance increased. Lima et al. [12] carried out an updated evaluation of recent advancements and recommendations for improving the operation of absorption refrigeration systems using various working fluids. Because of the low temperature of the ammonia operation, ammonia-water pair is used in air conditioning and industrial processes. Solar energy is used as a source of input to improve the efficiency of absorption cooling systems.

Jain et al. [13] assessed the thermodynamic potentials and related risks of $\mathrm{NH}_{3}-\mathrm{H}_{2} \mathrm{O}$ and $\mathrm{H}_{2} \mathrm{O}-\mathrm{LiBr}$ integrated vapour absorption refrigeration (IVARS). Their proposed design keeps an evaporator temperature of $92.1^{\circ} \mathrm{C}$ at $30^{\circ} \mathrm{C}$, which is $51.6^{\circ} \mathrm{C}$ lower than the required VARS-standard cooling temperature for the same cooling task. This issue is addressed with exergy analyses. Surprisingly, 19.8 percent of the IVARS irreversible loss was proven to be preventable by adjusting the efficiency settings of various IVARS components, whereas the remaining $93.7 \%$ was determined to be irreversible. The results showed that IVARS performs better and may be used with low-temperature waste heat recovery.

Tetemke et al. [14] studied the influence of several design and operation scenarios on the COP of the cooling system which was established through simulation energy. AVAR system employing geothermal energy to provide waste thermal cooling, was investigated. For cooling a drinking water supply, from $37.8^{\circ} \mathrm{C}$ to $16^{\circ} \mathrm{C}$ in 16 hours, VARS components were analyzed utilizing mass and energy conservation principles. Furthermore, at an evaporation rate of $103.12 \mathrm{~kW}$, the VAR system could cool 66,000 litres of beverage water. These results show that the evaporation rate varies with time, VAR systems powered by geothermal energy.

As per the above literature, part of the ongoing search for alternative technologies that would use renewable energy sources, valuable alternatives such solar, geothermal, waste heat, are identified as sources for the standard vapourcompression mechanism. The novelty of this paper is, an alternate absorption refrigeration system with a novel design for higher refrigeration effect is developed by building the system into an existing ARS-GAX system, resulting in reduced losses, increased performance, and lower electrical energy consumption.

\section{MATERIALS AND METHODS}

The Absorption Refrigeration System consist of a pump, an absorber, a generator, a solution heat exchanger, a condenser, a rectifier, a refrigerant heat exchanger and an evaporator. A cooling absorption system using a binary solution of absorbent and refrigerant as a working fluid. The most commonly utilized fluid absorption systems in large buildings or plants for commercial and industrial cooling purposes are ammoniawater and LiBr-water systems. This study will look into a modified ammonia-water absorption cooling GAX system. The American Society of Heating, Refrigeration, and Air Conditioning Engineers (ASHRAE) promotes the design and implementation of HVAC, AV, and conditioning systems. The ASHRAE Handbook goes into great depth about how the twofluid absorption refrigeration system works.

The system is divided into two pressure limits: one for the generator and one for the evaporator. The high-pressure solution flows via the generator and solution heat exchanger which engrosses heat from the source, and finally the rectifier, which mixes the ammonia and water mixture. After the water content in the ammonia is separated, pure ammonia vapour goes to the condenser. The weak solution is recirculated through the absorber and solution heat exchanger. The refrigerant vapour is condensed into a liquid by losing heat to the surrounding environment via convection in the condenser. The liquid ammonia is further cooled using refrigerant heat exchanger and directed to the evaporator. The refrigerant reaches a temperature below saturation after passing through the rectifier and into the evaporator, and the heat is absorbed by the area to be cooled in the refrigerator, forcing the refrigerant to become vapour. The refrigerant is then sent to the solution heat exchanger, where it absorbs ammonia from the water, and the cycle repeats. The studies were carried out by adjusting the mass flow rate on the generator, condenser, absorber, and evaporator for various specified temperatures and calculating the COP

The temperature of the remaining coolant reduces by absorbing the coolant vapour, as a result of the "vaporisation process." Simultaneously, the solution becomes diluted as a 
result of the higher coolant content absorbed. It is referred to as "the absorption process." Because of its basic exothermic absorption process, heat must be rejected in the environment to sustain the product's absorption capacity. By utilizing heat energy, the refrigeration effect can be achieved in a variety of ways. Since the process cannot be finished concurrently, the cooling effect cannot be created continually. As a result, a new GAX cycle is designed that combines these two approaches to increase performance and offer continuous cooling. The COP of an absorption system is obtained from:

\section{COP}

cooling capacity of evaporator

$$
\begin{aligned}
& =\overline{\text { heat input to the generator }+ \text { work input to the pump }} \\
& =\frac{Q e}{Q g}
\end{aligned}
$$

The pump's effort is typically neglected in assessments since it is minor concerning the generator's heat input.

Overall, the absorption cycle performs poorly per unit energy input; however, system waste heat can be used to increase overall energy utilization. Ammonia/water $\left(\mathrm{NH}_{3} / \mathrm{H}_{2} \mathrm{O}\right)$ systems are typically employed when a lower temperature is required. Each system component is computed and summarized with mass and heat flow rates. The system's coefficient of performance is calculated for several temperature ranges.

\subsection{Ammonia-water single stage absorption refrigeration system}

A cooling cycle system consists of a heat exchanger, evaporator, absorber, pump, two flow limits (expansion valve), a heat exchanger solution, a generator, a rectifier, and a condenser. Figure 1 illustrates the layout and flows direction of an ammonia-water single-stage absorption cooling system's mixing of solution and ammonia vapour. The cycle is separated into two fluxes: one with an ammonia-water mix and one with ammonia vapour. Points (1-6) indicate the ammonium hydroxide solution cycle, whereas "the remaining points reflect the ammonia vapour cycle. The rich solution (1) is pumped through the solution heat exchanger (2) with higher pressure into the generator (3), where heat added to an ammonia-water vapour mixture, while the poor solution (4) is returned to the absorber via solution heat exchanger and flow restrictor $(5,6)$. The ammonia-water vapour is purified in the rectifier by condensing the water vapour in the combination into a liquid". The condenser receives both the water liquid and the pure ammonia vapour (7). While flowing through the condenser, ammonia vapour loses heat to the environment and cools into fluid ammonia (8). The ammonia fluid is further cooled by a coolant heat exchanger (9) before passing through a flow-limiting system (10) with a quick pressure drop, where it evaporates since the new pressure is lower than its saturation. At the new pressure and temperature, ammonia become saturated vapour. The temperature of the components is always lower than the optimal temperature. The evaporator collects the heat from the refrigerator and directs the saturated ammonia vapour to it. The ammonia vapour (11) is absorbed into the water by the absorber after passing through the heat exchanger a second time (12). To restart the process, the generator delivers the ammonia-water vapour mixture to the rectifier (13), and the rectifier sends the water liquid back to the generator (14).

Several fluids are being studied, and the potentiality of the same was checked. The low circulation rate of the working fluid and low generator temperature are the challenges in making VAS - GAX employable. Recent works are reported on the binary working fluids for the absorption cycles.

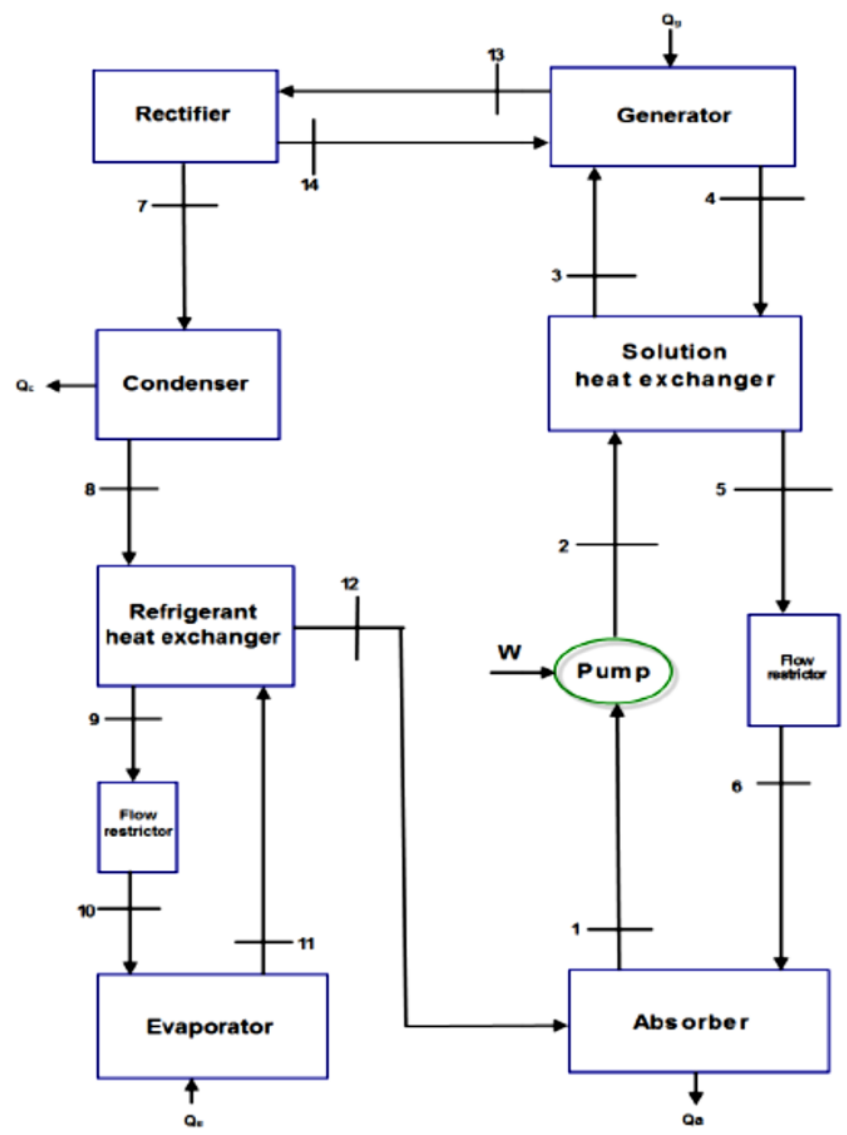

Figure 1. Ammonia water single stage absorption refrigeration system

\subsection{LiBr/water absorption refrigeration systems}

There are two significant advantages of using "LiBr/water" for absorption refrigeration systems: $\mathrm{LiBr}$ is a non-volatility absorbent (no need for a rectifier) with an unusually high heat of vaporisation of water (refrigerant). Low-temperature applications, however, are limited to that above $0^{\circ} \mathrm{C}$ due to the usage of water as a refrigerant. The system must be run under a vacuum because the refrigerant used is water. The solution is prone to crystallization at high concentration. Some metals are also prohibitively expensive and corrosive. For improving heat mass transport capacities, some additives are added to $\mathrm{LiBr} /$ water as a corrosion inhibitor. Therefore, an ammonia/water $\left(\mathrm{NH}_{3} / \mathrm{H}_{2} \mathrm{O}\right)$ absorption system is most commonly used where a lower temperature is required. The high concentration (rich solution) of ammonia (0.56 or 56\%) is used in the present system comparing to conventional system $(0.38)$ to increase the performance of the combined system/cycle.

Although $\mathrm{LiBr}$ /water and $\mathrm{NH}_{3}$ /water are used extensively for several years, essential studies on novel fluids have been done. For example, refrigerants were used to study fluorocarbon working fluids. Furthermore, because of its high solubility in many organic solvents, researchers suggested R22 and R21 widely. In addition, Dimethylformamide (DMF) and dimethyl ether of Tetra Ethylene Glycol (DMETEG) are used as emerging solvents. 


\subsection{Improvement of absorption process}

The absorber is a vital component in any vapour absorption system. The mass flow rate of refrigerant per unit of refrigerant produced was discovered in an experimental study, to be two to five times higher than the theoretical value. This is due to an imbalance in the absorber. The solution absorbs fewer refrigerants than the forecast value at a particular temperature and pressure in the absorber. Many studies were performed to optimize the absorption process and understand better between the solution and vapour chillers.

The most prevalent absorber type in the absorbent system was the absorption of vapour coolant into a decaying solution layer atop chilled horizontal tubes. In this type of absorber, heat is absorbed from the liquid layer during the absorption process. Thus, it speeds up the absorption process. However, for optimal performance, this design necessitates a high recirculation rate. Another unique method is the absorption of a vapour-refrigerant in a liquid cover on cooled revolving discs [15]. As a result, the absorption of the spinning discs for a given surface area is significantly greater than in a standard configuration. Based on this design, the size of an absorber used is much smaller than a conventional system.

\section{GAX-VAS COMBINED CYCLE}

A GAX-VAS combined unit is built up of a generator, HP GAX, condenser, absorber, pre-cooler, economizer, expansion valve, and shell and tube chiller, as shown in Figure 2.

The generator's heat source is steam, evaporating the refrigerant in a vapour state and storing the lean mixture in the lean tank at the generator's bottom. To transmit ammonia vapour to HP GAX and then to the unit, a condenser, precooler, absorber, and absorber are utilized. The lower temperature section rejects heat out to the surroundings and the rich-refrigerant solution is preheated in the higher temperature section of the absorber. Thus, $10 \%$ COP is improved due to decrease in heat input to the generator [15]. The absorber's liquid refrigerant is sent to the ammonia reservoir before being routed to the chiller through the economizer and expansion valve. Sub-cooling is produced in the economizer to boost cooling capacity. The expansion valve regulates refrigerant flow and relieves pressure from the liquid refrigerant, allowing it to expand. The shell and tube chiller generates chilled air at a low temperature, which is then provided to the cooled region. When compared to standard compression systems, the GAX unit in the present study produces best performance and more efficiently chilled air for industrial cooling applications.

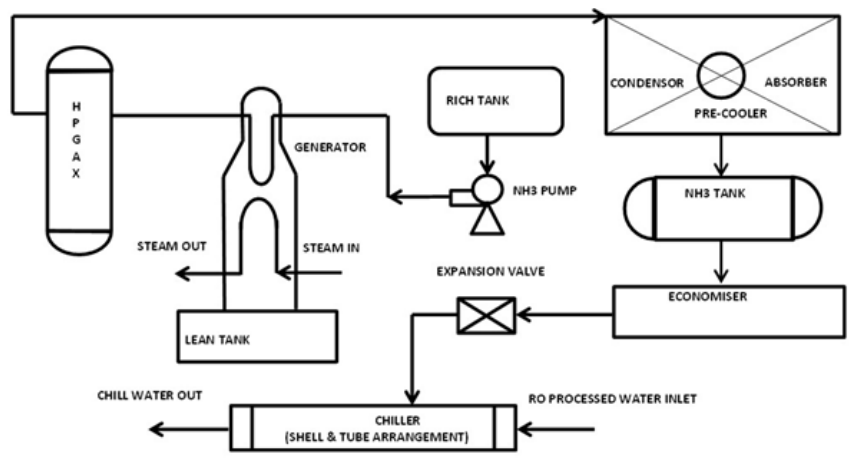

Figure 2. Layout of GAX-VAS combined cycle employed

\subsection{Operational procedures of VAS-GAX absorption system}

These plants work with the binary system of ammoniawater solution with ammonia as a refrigerant. The system is similar in operation to the mechanical compressor by simulating operations with thermal compression from low to high-pressure side, split into three stages.

Refrigerant vapour at evaporation pressure (low pressure) is absorbed by ammonia-water solution (poor liquor getting enriched by ammonia) in the absorber. Heat rejection occurs here due to heat of solution and condensation, and this is done by air cooling.

Enriched solution (rich liquor) is transferred to the highpressure side to distiller employing rich pump through various heat exchangers.

Ammonia vapour and poor liquor is separated in the generator from the enriched solution under high pressure. The vapour mixture is improved in ammonia content by HP GAX and then liquefied in an Air-cooled condenser. The remaining poor solution is cooled in a solution exchanger, expanded to Absorber and has then the ability to absorb refrigerant in an air-cooled cycle.

Chiller has a shell side filled with $\mathrm{NH}_{3}$. Water flows in tube side imparting its heat to liquid $\mathrm{NH}_{3}$ and transferring cold. $\mathrm{NH}_{3}$ vapour flows to Absorber through separator. The lean liquor coming from the shell side of the solution exchanger absorbs the $\mathrm{NH}_{3}$ vapour flows to absorber. The heat of dissolution by absorption of $\mathrm{NH}_{3}$ in Lean liquor is getting cooled by air cooling. The cooled enriched $\mathrm{NH}_{3}$ solution is pumped by solution pump through HP GAX solution exchanger to lean cooler/generator. In the generator, steam is used to liberate $\mathrm{NH}_{3}$ vapour. This is passed through HP GAX where it's rectified by losing heat to the rich solution which is passing through the tubes. Cooled and enriched $\mathrm{NH}_{3}$ vapour flows to the condenser whereby air cooling condenses this to pure liquid $\mathrm{NH}_{3}$ to complete the cycle for the evaporator, in a closed-loop cycle.

\subsection{Cold run simulation operation}

Except for the chiller, condenser and economizer, other heat exchangers will be under through circulation of $\mathrm{NH}_{3}$ liquor. It is better to remove mill scale, dust and other debris in this equipment by first circulating with cold water and draining it. The circulation pump is fitted with a suction strainer to trap heavier particles. The operation involves isolating pure $\mathrm{NH}_{3}$ circuit, pressurizing HP side with compressed air, adding water and circulating the same with the level in Rich tank and Lean tank in normal position.

- Close $\mathrm{NH}_{3}$ liquid from the condenser to chiller.

- Open Absorber top valve and connect soft water filling hose.

- Add compressed air to the condenser through the top valve and pressurize $4-5 \mathrm{~kg} / \mathrm{cm}^{2}$. Check there is no leak in all flanged joints.

- Start rich pump slowly and establish full circulation.

- Stop the water when levels are established.

- Adjust pump discharge valve or let down valves.

- Continue circulation for 2 hours and drain total dirty water from the lowest point after stopping the pump.

- Clean pump suction filter.

- Vent condenser to atmospheric condition.

Repeat this till circulating water is clear. 


\subsection{Hot run simulation}

The same operation of cold running is repeated with steam circulated to the generator and the Axial fan should be ON this will cool down the Absorber and condenser. Here again, soft water is used for cleaning the system with a level maintained.

After doing all operations till steam supply is started. The steam valve is to be slowly opened to give circulating water temperature as $110^{\circ} \mathrm{C}$ maximum. Continue circulation of chilled water for 2 hours. Stop steam and stop circulation pump. Drain all dirty water from the lowest drain point. Clean pump suction filter. Vent condenser to atmospheric condition.

\subsection{Initial filling}

Water: The following equipment is to be filled with mixture of Dimethylformamide (DMF) solvent water for chemical reactions.

- $\quad$ Rich tank, Solution exchanger and Shell and tube side.

- Generator Bottom, Pumps and pipeline.

- Do filling of water.

- Start pump on re-circulation.

- Keep Axial Fan ON Always.

- Fill chiller with $\mathrm{NH}_{3}$. Keep the Absorber vent open in a bucket of water and check that $\mathrm{NH}_{3}$ is not escaping. After rich tank pressure rises, take to liquor to the generator. Steam will pressurize the generator, and return ammonia to the condenser.

- Vent air from the condenser is dipped in a bucket of water and check that $\mathrm{NH}_{3}$ is not escaping.

- Isolate $\mathrm{NH}_{3}$ filling line after $\mathrm{NH}_{3}$ tank level is reached. All $\mathrm{NH}_{3}$ vapour is recovered by Lean solution in Absorber.

\subsection{HP side stabilization}

- $\mathrm{NH}_{3}$ condenses at $45^{\circ} \mathrm{C}$ when pressure is 17 bars. To reach this pressure generator steam addition and condenser Axial Fan Running is necessary.

- Check the rich pump is running and open the letdown valve.

- Ensure that level is not lost in the rich tank and lean level.
- Open steam valve slowly, checking the rise in pressure.

- Close condenser vent after checking all air is purged out of the system.

\subsection{Total stabilization}

- $\quad$ Stabilize pump circulation between low pressure (LP) and high pressure (HP) side after closing by-pass to the chiller. Vent all high points to purge the air block.

- Start chilled water circulation slowly and increase Absorber pressure.

- Circulate steam into generator slowly to bring the temperature to design

- Check Rich pump temperature remains at below $55^{\circ} \mathrm{C}$.

\subsection{Normal operation}

- When Chiller-Absorber pressure is going more than design, steam quantity is to be increased, to make it normal.

- When condenser pressure is going more than $19 \mathrm{~atm}$, check axial Fan is running. Reduce the steam flow to reduce the pressure.

- When chiller pressure is lowering chilled water flow is to be increased to extract colder or if a load is not needed, reduce steam.

- $\quad$ Check the level in, rich tank, Lean tank, $\mathrm{NH}_{3}$ tank.

- Check chiller and generator temperature conditions are normal.

Table 1 shows the pressure and temperature values taken during the experiments in different components of a GAXVAS system.

The system performance is more efficient because $\mathrm{NH}_{3}$ has a high latent heat of vaporization. The normal freezing point of $\mathrm{NH}_{3}$ is $-78^{\circ} \mathrm{C}$, so it can be used for low-temperature cooling applications. The rectifier is used in a cycle to strip away water that normally evaporates with $\mathrm{NH}_{3}$. since both $\mathrm{NH}_{3}$ and water are volatile. The water would accumulate in the evaporator and offset the system performance if rectifier is not used. The disadvantages of $\mathrm{NH}_{3}$ /water are toxicity, high pressure and corrosive action with copper and copper alloy used in the system. However, $\mathrm{NH}_{3}$ /water is available at low cost environmentally friendly.

Table 1. Experimental data on VAS-GAX

\begin{tabular}{ccccccccccc}
\hline Time $(\mathbf{p m})$ & $\mathbf{P}_{\mathbf{1}}$ & $\mathbf{P}_{\mathbf{2}}$ & $\mathbf{P}_{\mathbf{3}}$ & $\mathbf{P}_{\mathbf{4}}$ & $\mathbf{T}_{\mathbf{1}}$ & $\mathbf{T}_{\mathbf{2}}$ & $\mathbf{T}_{\mathbf{3}}$ & $\mathbf{T}_{\mathbf{4}}$ & $\mathbf{T}_{\mathbf{5}}$ & $\mathbf{T}_{\mathbf{6}}$ \\
\hline 2.30 & 16 & 2 & 0.25 & 4.1 & 47 & 130 & 50 & 40 & 32 & 32 \\
2.40 & 15.5 & 2 & 0.25 & 4.2 & 47 & 129 & 50 & 40 & 32 & 32 \\
2.50 & 16.5 & 1.75 & 0.175 & 4.6 & 48 & 129 & 50 & 40 & 32 & 29 \\
3.00 & 17 & 1.8 & 0.175 & 4.9 & 47 & 130 & 52 & 41 & 32 & 28.7 \\
3.10 & 17 & 1.6 & 0.15 & 4.6 & 46 & 129 & 52 & 41 & 30.5 & 27.5 \\
3.20 & 18.5 & 1.9 & 0.175 & 3.9 & 46 & 130 & 52 & 41 & 31 & 27 \\
3.30 & 17.5 & 1.5 & 0.2 & 4 & 47 & 129 & 52 & 40 & 31 & 27 \\
3.40 & 17 & 1.75 & 0.175 & 4.5 & 45 & 130 & 50 & 40 & 31 & 26.9 \\
3.50 & 17.5 & 2 & 0.2 & 4.4 & 47 & 128 & 50 & 40 & 30.5 & 25.6 \\
4.00 & 17 & 1.75 & 0.2 & 4 & 45 & 128 & 50 & 40 & 27.7 & 26 \\
4.10 & 18 & 1.8 & 25 & 4.9 & 46 & 124 & 50 & 40 & 27.2 & 25.4 \\
4.20 & 18 & 2 & 0.2 & 4.2 & 46 & 125 & 52 & 41 & 25.9 & 24.6 \\
4.30 & 16 & 1.5 & 0.15 & $\mathbf{P} 4$ & 45 & 124 & 52 & 40 & 25.3 & 24.6 \\
4.40 & 16.5 & 1.6 & 0.15 & 4.1 & 47 & 124 & 52 & 40 & 25.5 & 24.6 \\
4.50 & 17 & 2 & 0.15 & 4.2 & 46 & 126 & 52 & 40 & 25.4 & 24.7 \\
5.00 & 16.5 & 1.8 & 0.15 & 4.6 & 46 & 128 & 52 & 40 & 25.9 & 25.2 \\
\hline
\end{tabular}

Note: $\mathrm{P}_{1}$ - HP, $\mathrm{P}_{2}-$ LP, $\mathrm{P}_{3}$-Water Pressure, $\mathrm{P}_{4}$ - Steam Pressure, $\mathrm{T}_{1}$-Pump outlet, $\mathrm{T}_{2}$-Lean outlet, $\mathrm{T}_{3}$-Generator Inlet, $\mathrm{T}_{4}-\mathrm{C}_{\text {- }}$ outlet. 
Table 2. Inlet and outlet temperature of major components in a system

\begin{tabular}{ccccc}
\hline Water & Generator & Condenser & Absorber & Evaporator \\
\hline Inlet Temperature & $100^{\circ} \mathrm{C}$ & $20^{\circ} \mathrm{C}$ & $20^{\circ} \mathrm{C}$ & $20^{\circ} \mathrm{C}$ \\
Outlet Temperature & $90^{\circ} \mathrm{C}$ & $24^{\circ} \mathrm{C}$ & $24^{\circ} \mathrm{C}$ & $12^{\circ} \mathrm{C}$ \\
\hline
\end{tabular}

Table 3. Governing equations for major components of GAX-VAS system

\begin{tabular}{|c|c|c|c|}
\hline Generator & Condenser & Evaporator & Absorber \\
\hline $\begin{array}{c}\mathrm{Qg}_{+}+\mathrm{Q}_{3}=\mathrm{Q}_{4}+\mathrm{Q}_{7} \\
\mathrm{Q}_{3}=\mathrm{m}_{3} \cdot \mathrm{h}_{3} \\
\mathrm{Q}_{4}=\mathrm{m}_{4} \cdot \mathrm{h}_{4} \\
\mathrm{Q}_{7}=\mathrm{m}_{7} \cdot \mathrm{h}_{7}\end{array}$ & $\begin{array}{c}\mathrm{Q}_{\mathrm{c}}+\mathrm{Q}_{8}=\mathrm{Q}_{7} \\
\mathrm{Q}_{8}=\mathrm{m}_{8} \cdot \mathrm{h}_{8} \\
\mathrm{Q}_{7}=\mathrm{m}_{7} \cdot \mathrm{h}_{7}\end{array}$ & $\begin{array}{c}\mathrm{Qe}_{+} \mathrm{Q}_{9}=\mathrm{Q}_{10} \\
\mathrm{Q}_{9}=\mathrm{m}_{9} \cdot \mathrm{h}_{9} \\
\mathrm{Q}_{10}=\mathrm{m}_{10} \cdot \mathrm{h}_{10}\end{array}$ & $\begin{array}{c}\mathrm{Q}_{\mathrm{a}}+\mathrm{Q}_{1}=\mathrm{Q}_{6}+\mathrm{Q}_{10} \\
\mathrm{Q}_{1}=\mathrm{m}_{1} \cdot \mathrm{h}_{1} \\
\mathrm{Q}_{6}=\mathrm{m}_{6} \cdot \mathrm{h}_{6} \\
\mathrm{Q}_{10}=\mathrm{m}_{10} \cdot \mathrm{h}_{10}\end{array}$ \\
\hline $\begin{array}{c}m_{3} \cdot X_{3}=m_{4} \cdot X_{4} \\
m_{1}=\frac{m_{4} \cdot x_{s}}{x_{w}} \\
m_{6}=\frac{m_{10}}{\left(1-x_{6} / x_{1}\right)}\end{array}$ & & \rangle & $\mathrm{T} 5=-\varepsilon-\frac{T 4}{(T 4-T 2)} x(T 4-T 2)$ \\
\hline$h(T, X)=100 \sum_{i=1}^{16} a_{i}\left[\frac{T}{273.16}-1\right.$ & $1]^{m_{i}}(X)^{n_{i}}$ & \multicolumn{2}{|c|}{ - Enthalpy at all thermodynamic state calculated with the help of Table 3} \\
\hline $\begin{array}{c}\mathrm{Q}_{\mathrm{g}}=\left(\mathrm{m}_{7} \times \mathrm{h}_{7}\right)+\left(\mathrm{m}_{4} \times \mathrm{h}_{4}\right)-\left(\mathrm{m}_{3} \times \mathrm{h}_{3}\right) \\
\mathrm{Q}_{\mathrm{g}}=\mathrm{m}_{11} \times 4.2 \times\left(\mathrm{T}_{12}-\mathrm{T}_{11}\right)\end{array}$ & $\begin{array}{l}\mathrm{Q}_{\mathrm{c}}=\left(\mathrm{m}_{7} \times \mathrm{h}_{7}\right)-\left(\mathrm{m}_{8} \times \mathrm{h}_{8}\right) \\
\mathrm{Q}_{\mathrm{c}}=\mathrm{m}_{15} \times 4.2 \times\left(\mathrm{T}_{16}-\mathrm{T}_{15}\right)\end{array}$ & $\begin{array}{l}\mathrm{Qe}=\left(\mathrm{m}_{10} \times \mathrm{h}_{10}\right)-\left(\mathrm{m}_{9} \times \mathrm{h}_{9}\right) \\
\mathrm{Qe}=\mathrm{m}_{17} \times 4.2 \times\left(\mathrm{T}_{18}-\mathrm{T}_{17}\right)\end{array}$ & $\begin{array}{c}\mathrm{Qa}=\left(\mathrm{m}_{6} \times \mathrm{h}_{6}\right)+\left(\mathrm{m}_{10} \times \mathrm{h}_{10}\right)-\left(\mathrm{m}_{1} \times \mathrm{h}_{1}\right) \\
\mathrm{Qa}=\mathrm{m}_{13} \times 4.2 \times\left(\mathrm{T}_{14}-\mathrm{T}_{13}\right)\end{array}$ \\
\hline $\begin{array}{l}\mathrm{m} 11 \\
=\frac{(m 7 x h 7)+(m 4 x h 4)-(m 3 x h 3)}{42 x(T 11-T 12)}\end{array}$ & $=\frac{(m 7 x h 7)-(m g x h g)}{42 x(T 16-T 15)}$ & $\begin{array}{l}\mathrm{m} 17 \\
=\frac{(m 10 \times h 10)-(m 9 \times h 9)}{42 \times(T 18-T 17)}\end{array}$ & $\begin{array}{l}\mathrm{m} 13 \\
=\frac{(m 6 \times h 6)+(m 10 \times h 10)-(m 1 x h 1)}{42 \times(T 14-T 13)}\end{array}$ \\
\hline
\end{tabular}

Table 4. Coefficient of the enthalpy equation

\begin{tabular}{cccc}
\hline Sl No & $\mathbf{m}_{\mathbf{i}}$ & $\mathbf{n}_{\mathbf{i}}$ & $\mathbf{a}_{\mathbf{i}}$ \\
\hline 1 & 0 & 1 & -7.6108 \\
2 & 0 & 4 & 25.6395 \\
3 & 0 & 8 & -247.092 \\
4 & 0 & 9 & 325.952 \\
5 & 0 & 12 & -158.854 \\
6 & 0 & 14 & 61.9084 \\
7 & 1 & 0 & 14.1314 \\
8 & 1 & 1 & 1.18157 \\
9 & 2 & 1 & 2.84179 \\
10 & 3 & 3 & 7.41609 \\
11 & 5 & 3 & 891.844 \\
12 & 5 & 4 & -1613.09 \\
13 & 5 & 5 & 622.106 \\
14 & 6 & 2 & -207.588 \\
15 & 6 & 4 & -6.87393 \\
16 & 8 & 0 & 3.50716 \\
\hline
\end{tabular}

The governing equations and the co-efficient used for the performance analysis for major components of GAX-VAS System are shown in Table 3 and 4 . The system is divided into two sections with pressure limits, one for generator temperature $\left(\mathrm{T}_{7}\right)$ and another for evaporator temperature $\left(\mathrm{T}_{10}\right)$, with $\mathrm{P}_{1}=\mathrm{P}_{6}=\mathrm{P}_{9}=\mathrm{P}_{10}$ corresponding to low pressure and $\mathrm{P}_{2}$ $=\mathrm{P}_{3}=\mathrm{P}_{4}=\mathrm{P}_{5}=\mathrm{P}_{7}=\mathrm{P}_{8}$ corresponding to high pressure.

\subsection{Input data for the experiment}

- Refrigerant mass flow rate $=0.05 \mathrm{~kg} / \mathrm{s}$

- Heat exchanger effectiveness $=0.7$

- Temperature at Generator $\quad=\mathrm{T}_{\mathrm{G}}=\mathrm{T}_{4}=\mathrm{T}_{7}=50^{\circ} \mathrm{C}$

- Temperature at Condenser $\quad=\mathrm{T}_{\mathrm{C}}=\mathrm{T}_{8}=50^{\circ} \mathrm{C}$

- Temperature at Absorber $\quad=\mathrm{T}_{\mathrm{A}}=\mathrm{T}_{1}=\mathrm{T}_{2}=20^{\circ} \mathrm{C}$

- Temperature at Evaporator $\quad=\mathrm{T}_{\mathrm{E}}=\mathrm{T}_{10}=\mathrm{T}_{9}=2.5^{\circ} \mathrm{C}$

- Weak solution concentration $=\left(\mathrm{X}_{\mathrm{w}}\right)=55.3 \%$

- Strong solution concentration $=\left(X_{\mathrm{s}}\right)=56 \%$

\section{SOLUBILITY DATA OF NH3 IN WATER}

\subsection{Chiller}

Figure 3 illustrates the liquid $\mathrm{NH}_{3}$ vapour PressureTemperature relationship in chiller or evaporator. At $4 \mathrm{~kg} / \mathrm{cm}^{2}$, operating pressure, evaporator temperature is $4^{\circ} \mathrm{C}$.

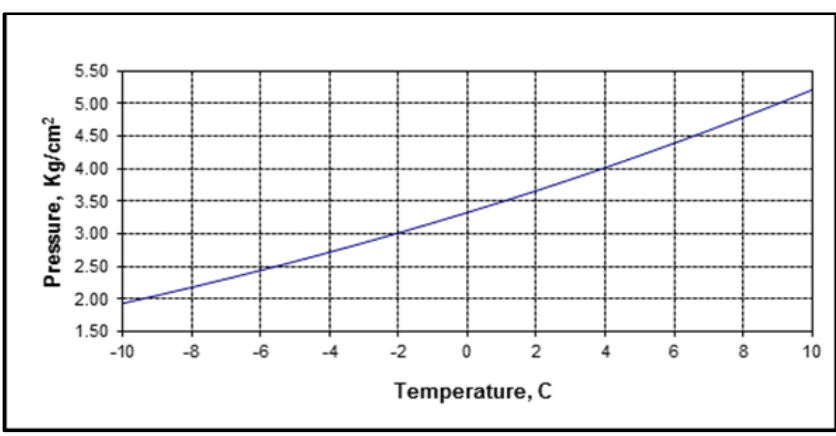

Figure 3. Variation of pressure with the temperature at Chiller

\subsection{Condenser}

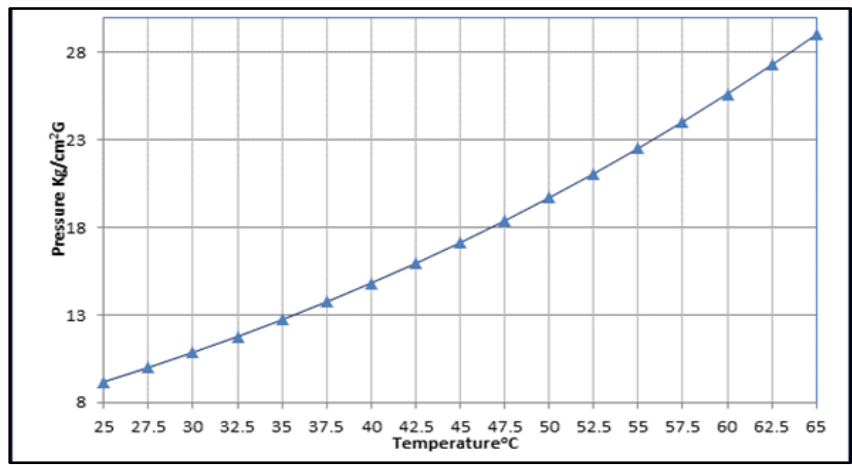

Figure 4. Variation of pressure with the temperature at Condenser 
Figure 4 illustrates the liquid $\mathrm{NH}_{3}$ vapour PressureTemperature relationship in condenser. For $50^{\circ} \mathrm{C}$ temperatures in condenser by running Axial Fan operating pressure is 19.7 $\mathrm{kg} / \mathrm{cm}^{2}$.

\subsection{Absorber}

Figure 5 illustrates the solubility data of $\mathrm{NH}_{3}$ in water in absorber under pressure and particular temperature. At achieved absorber bottom temperature of $49^{\circ} \mathrm{C}$ with chiller operating at $4 \mathrm{~kg} / \mathrm{cm}^{2}, 42 \%$ rich $\mathrm{NH}_{3}$ concentration obtained from absorber.

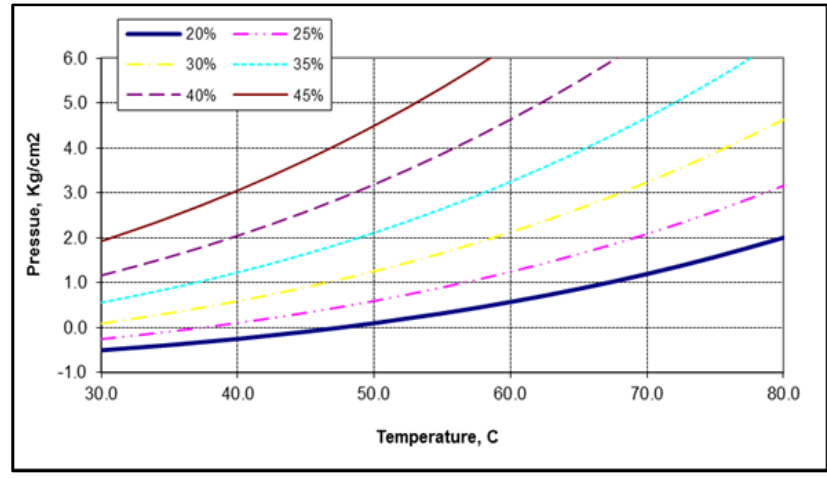

Figure 5. Variation of pressure with the temperature at Absorber

\subsection{Generator}

Figure 6 illustrates the solubility values of $\mathrm{NH}_{3}$ in water in the generator under pressure and a particular temperature maintained by heating. At maintained bottom distiller temperature of $140^{\circ} \mathrm{C}$ and with condenser pressure of 17 $\mathrm{kg} / \mathrm{cm}^{2}$ achieved by running Axial Fan, 24\% $\mathrm{NH}_{3}$ concentration obtained from generator. Depletion of concentration is $18 \%$.

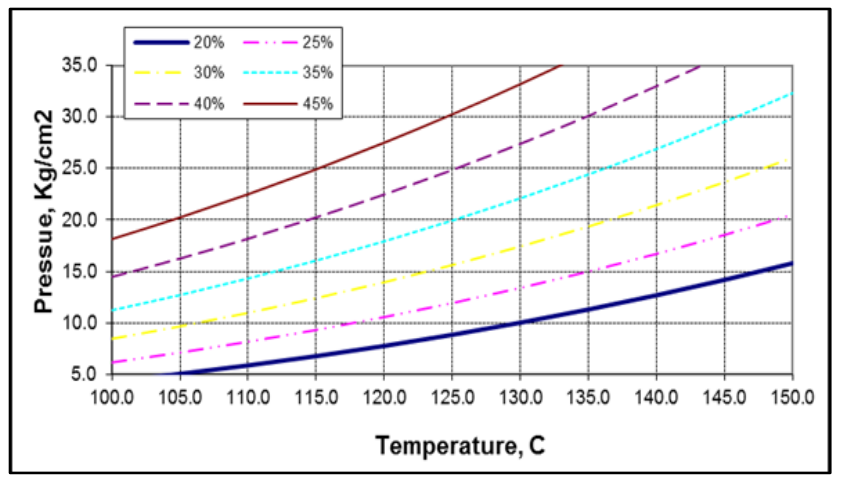

Figure 6. Variation of pressure with the temperature at Generator

\section{RESULTS AND DISCUSSIONS}

\subsection{Thermodynamic analysis of VAS-GAX system}

To conduct thermodynamic analysis of the proposed Vapour Absorption Cooling System (VACS), the following assumptions are made: There are no pressure variations other than those induced by the flow pump. At points 1, 4, and 8 , only Saturated Liquid exists, but Saturated Vapor exists at point 10. Pumping is an entirely isentropic operation. Assume that the weak solution is cooler and less absorbent, whereas the robust solution is more absorbent and cooler. The percentage of weak solutions in states 1-3 will stay unchanged, as will the percentage of strong solutions in states 4-6. "Temperatures at Thermodynamic States 11, 12, 13, 14, 15, 16, 17 , and 18 represent the external water circuit used to give heat to the system's components", as shown in Figure 1. The inlet and outlet temperatures of the major components of the absorption system is illustrated in Table 2 .

\subsection{Performance (COP) analysis of VAS-GAX system}

The working fluid's chemical and thermodynamic properties are critical to the performance of absorption refrigeration systems. A critical condition for absorbent/refrigerant combinations is that they have a margin of miscibility in the liquid phase within the operational temperature range of the cycle. It must also be chemically stable, non-toxic, and non-explosive. In addition to these requirements, the following are desirable.

The difference in boiling point pressure between the pure refrigerant and the combination known as boiling elevation should be as significant as possible at the same pressure. The coolant must have a high heat of vaporization and a high concentration within the absorbent to maintain a low circulation rate between the generator and the absorbent per unit of cooling capacity. Heat and mass transfer are influenced by transport properties such as viscosity, thermal conductivity, and diffusion coefficient, which should all be favourable. Both the refrigerant and the absorbent should be non-corrosive, nonharmful to the environment, and affordable.

\subsubsection{Generator}

Figure 7 depicts the variation of COP with generator temperature. The results show that when the generator temperature rises, the Coefficient of Performance decreases due to corresponding enthalpy. This is because the generator load rises due to an increase in refrigerant enthalpy. The key advantage of this cooling system is that it can function at a low generator temperature to a low evaporator temperature while maintaining an appropriate COP system. Because fluid temperatures are generally low from this type of heat source, it can then use heat and solar industrial or civil wastes

Figure 8 shows the heat input to the generator corresponding to the generator temperature. The result clearly shows that as the generator temperature increases the rate of heat supplied to generator decreases due to increase of absorber heat rejection rate.

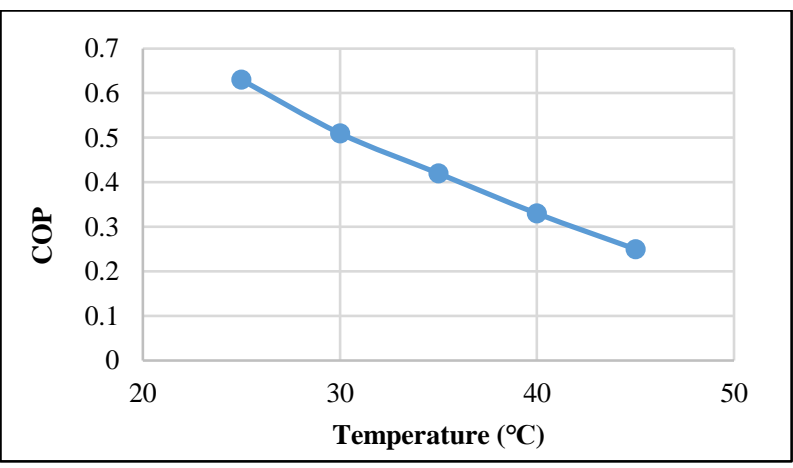

Figure 7. Variation of COP with generator temperature 




Figure 8. Variation of heat supply with generator temperature

\subsubsection{Absorber}

The link between COP and absorber temperature is depicted in Figure 9. The results show that when the temperature of the absorber decreases, so does the system's Coefficient of Performance. Because the generator load has dropped, this is the case.

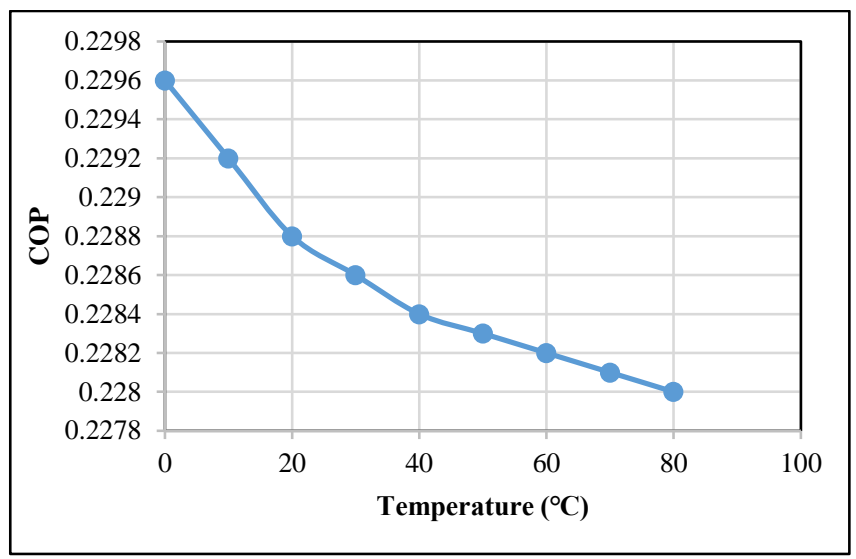

Figure 9. Variation of COP with absorber temperature

\subsubsection{Evaporator}

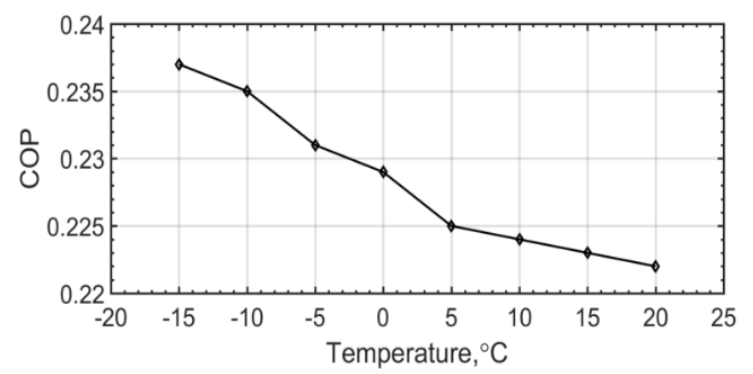

Figure 10. Variation of COP with evaporator temperature

The basic function of an evaporator in the refrigerator system is to remove the heat from the water, air, and other substances present in the refrigerator. The evaporators of refrigerator systems act as a heat exchanger which helps in transferring the heat from the substance and make it cool. The $\mathrm{COP}$ variation as a function of evaporator temperature is illustrated in Figure 10. As the evaporator temperature rises, the system's coefficient of performance appears to decrease with constant generator, condenser, and absorber temperatures. This is due to an increase in evaporator load. COP decreases with the increase of thermal load; this is because of higher operating temperature and pressure of condenser. The literature study reveals that $75 \%$ load condition in the evaporator gave better results in terms of higher refrigeration effect and COP [15].

\section{CONCLUSIONS}

A modified VAS-GAX refrigeration system is fabricated with modern design and analyzed the experimental data to improve performance compared to the existing systems. The current system has a high COP when compared to existing VCS and VAS. The maximum COP obtained from the modified GAX system based on a greater generator temperature is 0.63 which is higher than that $(0.1-0.3)$ of the standard absorption refrigeration system. In addition, the GAX cycle requires less electricity, since the system replaces the compressor. Also, the losses due to mechanical components are reduced. Further, the environmental damages were reduced due to the usage of non-toxic refrigerants. The modified VASGAX system is used for industrial applications due to highperformance values. Thus, the research on VAS-GAX system shall be extended by the researchers for more performancebased on commercial and indusial cooling applications.

\section{ACKNOWLEDGMENT}

The author declares and acknowledges receipt of funding from AICTE-RPS, Government of India, for a pilot project for Fabricating and experimentally analyze the performance of the GAX absorption system for cooling applications.

\section{REFERENCES}

[1] Jain, V., Sachdeva, G., Kachhwaha, S.S. (2015). Energy, exergy, economic and environmental (4E) analyses based comparative performance study and optimization of vapor compression-absorption integrated refrigeration system. $\quad$ Energy, 91: 816-832. https://doi.org/10.1016/j.energy.2015.08.041

[2] Dubey, A.M. (2020). Modified vapour absorption refrigeration cycles. International Journal of Ambient Energy, $\quad 74$ : 1-7. https://doi.org/10.1080/01430750.2020.1720807

[3] Srivastava, S., Sen, R.K., Thakur, A., Tated, M.K. (2015) Review paper on analysis of vapour absorption refrigeration system. International Journal of Research in Engineering and Technology, 4(6): 410-413.

[4] Boudéhenn, F., Bonnot, S., Demasles, H., Lefrançois, F., Perier-Muzet, M., Triché, D. (2016). Development and performances overview of ammonia-water absorption chillers with cooling capacities from 5 to $100 \mathrm{~kW}$. Energy Procedia, 91: 707-716. https://doi.org/10.1016/j.egypro.2016.06.234

[5] Osta-Omar, S.M., Micallef, C. (2017). Effect of the vapour-solution interface area on a miniature lithiumbromide/water absorption refrigeration system equipped with an adiabatic absorber. Energy Procedia, 118: 243247. https://doi.org/10.1016/j.egypro.2017.07.009

[6] Ramesh, R., Murugesan, S.N., Narendran, C., Saravanan, R. (2017). Experimental investigations on shell and 
helical coil solution heat exchanger in $\mathrm{NH}_{3}-\mathrm{H}_{2} \mathrm{O}$ vapour absorption refrigeration system (VAR). International Communications in Heat and Mass Transfer, 87: 6-13. https://doi.org/10.1016/j.icheatmasstransfer.2017.06.01 0

[7] Jain, V., Sachdeva, G., Kachhwaha, S.S. (2018) Comparative performance study and advanced exergy analysis of novel vapor compression-absorption integrated refrigeration system. Energy Conversion and Management, 172: 81-97. https://doi.org/10.1016/j.enconman.2018.06.116

[8] Al-Amir, Q.R., Khudair, N.Y. (2018). Theoretical analysis on the performance of branched GAX chiller cycle. The Iraqi Journal for Mechanical and Material Engineering, 18(4): 550-563.

[9] Ponshanmugakumar, A., Rajavel, R. (2019). Experimental analysis of vapour absorption generator integrated with thermal energy storage system. Materials Today: Proceedings, 16(2): 1158-1167. https://doi.org/10.1016/j.matpr.2019.05.209

[10] Talpada, J.S., Ramana, P.V. (2019). A review on performance improvement of an absorption refrigeration system by modification of basic cycle. International Journal of Ambient Energy, 40(6): 661-673. https://doi.org/10.1080/01430750.2017.1423379

[11] Praveen, P., Santhosh, S., Raaghul, R., Kumar, A.S.P. (2020). Performance analysis of vapour absorption refrigeration system using waste heat from IC engine. International Journal of Advanced Science and Technology, 29(5): 10879-10892.

[12] Lima, A.A., Leite, G.D.N., Ochoa, A.A., dos Santos, C.A., da Costa, J.A., Michima, P.S., Caldas, A. (2021). Absorption refrigeration systems based on ammonia as refrigerant using different absorbents: Review and $\begin{array}{lll}\text { applications. } & \text { Energies, } & \text { 14(1): }\end{array}$ https://doi.org/10.3390/en14010048

[13] Jain, V., Singhal, A., Sachdeva, G., Kachhwaha, S.S. (2020). Advanced exergy analysis and risk estimation of novel $\mathrm{NH}_{3}-\mathrm{H}_{2} \mathrm{O}$ and $\mathrm{H}_{2} \mathrm{O}-\mathrm{LiBr}$ integrated vapor absorption refrigeration system. Energy Conversion and Management, 224: 113348 . https://doi.org/10.1016/j.enconman.2020.113348

[14] Tetemke, Y., Paramasivam, V., Tadele, F., Selvaraj, S.K. (2021). Analyzed of vapor absorption refrigeration systems powered by geothermal energy: Site in Ethiopia. Materials Today: Proceedings, 46(17): 7570-7580. https://doi.org/10.1016/j.matpr.2021.01.642

[15] Srikhirin, P., Aphornratana, S., Chungpaibulpatana, S. (2001). A review of absorption refrigeration technologies. Renewable and Sustainable Energy Reviews, 5(4): 343 372. https://doi.org/10.1016/S1364-0321(01)00003-X

\section{NOMENCLATURE}

$B$

$C p$

$h$

$k$

$m$

$m_{i}, n_{i}, a_{i}$

$\mathrm{Nu}$

$P$

$Q$

$T$

$X$

\section{Greek symbols}

$\alpha$

$\beta$

$\phi$

$\theta$

$\mu$

$\Sigma$

\section{Subscripts}

$a$

$c$

$e$

$g$

$p$

$f$

$i$

$n f$

$1,2,3 \ldots$ dimensionless heat source length specific heat, J. $\mathrm{kg}^{-1}$. $\mathrm{K}^{-1}$

enthalpy $\mathrm{Kj} / \mathrm{kg}$

thermal conductivity, $\mathrm{W} \cdot \mathrm{m}^{-1} \cdot \mathrm{K}^{-1}$

Mass, kg

Co-efficient

local Nusselt number along the heat source

Pressure, $\mathrm{Nm}^{-2}$

Heat transfer at different components, $\mathrm{kJ}$

Temperature, $\mathrm{K}$

Concentration thermal diffusivity, $\mathrm{m}^{2}$. s-

thermal expansion coefficient, $\mathrm{K}^{-1}$

solid volume fraction

dimensionless temperature

dynamic viscosity, $\mathrm{kg} \cdot \mathrm{m}^{-1} \cdot \mathrm{s}^{-1}$

sum

absorber

condenser

evaporator

generator

nanoparticle

fluid (pure water)

terms

Nanofluid

state 